\title{
Communication \\ Ultra-Sensitive Intensity Modulated Strain Sensor by Tapered Thin-Core Fiber Based Modal Interferometer
}

\author{
Chuanxu Liu ${ }^{1}(0)$ Dexue Sun ${ }^{2}$, Jiuru Yang ${ }^{1,3, * \mathbb{C}}$, Hui Zhang ${ }^{1}$ and Lingling Ran ${ }^{1}$ \\ 1 College of Electronics Engineering, Heilongjiang University, Harbin 150080, China;

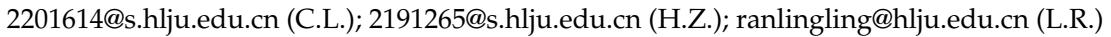 \\ 2 Goertek Limited Company, Weifang 261031, China; 2191353@s.hlju.edu.cn \\ 3 Heilongiiang Provincial Key Laboratory of Metamaterials Physics and Device, Heilongjiang University, \\ Harbin 150080, China \\ * Correspondence: yangjr@hlju.edu.cn
}

\section{check for}

updates

Citation: Liu, C.; Sun, D.; Yang, J.; Zhang, H.; Ran, L. Ultra-Sensitive Intensity Modulated Strain Sensor by Tapered Thin-Core Fiber Based Modal Interferometer. Photonics 2021, 8, 372. https://doi.org/10.3390/photonics 8090372

Received: 12 August 2021

Accepted: 1 September 2021

Published: 3 September 2021

Publisher's Note: MDPI stays neutral with regard to jurisdictional claims in published maps and institutional affiliations.

Copyright: (c) 2021 by the authors. Licensee MDPI, Basel, Switzerland. This article is an open access article distributed under the terms and conditions of the Creative Commons Attribution (CC BY) license (https:// creativecommons.org/licenses/by/ $4.0 /)$

\begin{abstract}
In this paper, to enhance practicality, a novel tapered thin-core fiber ( $t$-TCF) based modal interferometer is proposed and demonstrated experimentally. The light field distribution of $t$-TCF structure is investigated by a beam propagation method, and the quantitative relationship is gained between light intensity loss and waist diameter. Under $\sim 30 \mu \mathrm{m}$ waist diameter, multiple $t$-TCF based sensor heads are fabricated by arc-discharged splicing and taper techniques, and comprehensive tests are performed with respects to axial strain and temperature. The experimental results show that, with near-zero wavelength shift, obvious intensity strain response is exhibited and negativeproportional to the reduced length of TCF. Thus, the maximum sensitivity reaches $0.119 \mathrm{~dB} / \mu \varepsilon$ when the TCF length is equal to $15 \mathrm{~mm}$, and a sub-micro-strain detection resolution (about $0.084 \mu \varepsilon$ ) is obtained. Besides, owing to the flat red-shifted temperature response, the calculated cross-sensitivity of our sensor is compressed within $0.32 \mu \varepsilon /{ }^{\circ} \mathrm{C}$, which is promising for high precision strain related engineering applications.
\end{abstract}

Keywords: fiber-optic sensing; modal interference; thin-core fiber; strain; intensity; taper

\section{Introduction}

Fiber-optic strain sensors have the advantages of a compact structure, light weight and anti-electromagnetic interference, which has been widely used in high precision measurement, health-monitoring of building structures and aerospace engineering [1-5]. Strain sensors based on fiber Bragg grating (FBG) [6,7], long-period fiber grating (LPFG) [8,9], polymer optical fiber (POF) [10-12] and photonic crystal fiber (PCF) $[13,14]$ are easy to fabricate, but the sensitivity is usually only $\sim 1 \mathrm{pm} / \mu \varepsilon$. To improve sensitivity, the modal interference based fiber optic strain sensors, derived from the excitation of higher-order cladding modes, has received much attention [15-17]. PCF-based modal interferometers are proposed, and a $2-3 \mathrm{pm} / \mu \varepsilon$ strain sensitivity is reported with ultralow temperature cross-talk [18-20]. Du et al. enhanced the sensitivity of fiber grating sensors based on a four-wave mixing (FWX) mechanism, and the corresponding strain sensitivity reached $13.3 \mathrm{pm} / \mu \varepsilon$ [21]. Furthermore, Han made high birefringence PCF via a filling high refractive index (RI) liquid, and the maximum strain sensitivity of the interferometer was $25 \mathrm{pm} / \mu \varepsilon$ [22]. Liu et al. prepared a hybrid silica-polymer fiber sensor to gain the sensitivity of $28 \mathrm{pm} / \mu \varepsilon$ under an ultrahigh pressure condition [23]. In addition, Ruan and Yin respectively fabricated the bubble based micro-cavity interferometers through precise arc-discharge control, and the strain sensitivities were further increased to more than $30 \mathrm{pm} / \mu \varepsilon[24,25]$. Moreover, the highest sensitivity so far reached $1.15 \mathrm{~nm} / \mu \varepsilon$ in the range of $0 \sim 230 \mu \varepsilon$, through a cascaded micro-cavity structure [26]. Compared with wavelength sensitive structures, the intensity demodulation schemes can greatly improve the practicability and portability of sensors without an expensive and heavy high-precision 
spectrometer [27]. Zhang et al. proposed an intensity modulation scheme by using a piece of micro-structure hollow-core fiber (MS-HCF), but the presented sensitivity was less than $0.004 \mathrm{~dB} / \mu \varepsilon$ [28]. Wang et al. prepared a Mach-Zehnder interferometer (MZI) based on the series connection of LPG and up-taper, with a strain sensitivity of $0.026 \mathrm{~dB} / \mu \varepsilon$ in the range of $0-590 \mu \varepsilon$ [29]. The intensity sensitivity was further enhanced to $0.051 \mathrm{~dB} / \mu \varepsilon$ by a multimode and microfiber assisted open-cavity structure (MMA-OC), but with a complex fabrication process [30]. Comparatively, thin-core fiber based modal interferometers have been widely investigated and used in the RI sensing and gas concentration measurement [31,32], and the intensity sensitivity of $442.59 \mathrm{~dB} / \mathrm{RIU}$ was obtained by a down-taper structure [33]. Similarly, our group developed the study on the thin-core fiber based axial strain sensing, and the sensitivity of $\sim 0.02 \mathrm{~dB} / \mu \varepsilon$ was presented with a high temperature consistency $[34,35]$.

In this paper, through arc-discharge splicing and taper techniques, a novel tapered thin core fiber ( $t$-TCF) based in-fiber MZI is proposed and completed. With the varied waist diameter, the evanescent wave field distributions of $t$-TCF are analyzed, and the quantitative light intensity loss is obtained by beam propagation method. Under the suitable waist diameter, multiple $t$-TCF structures with different lengths are fabricated, and their axial strain characteristics are comprehensively tested. The experimental results show that our sensors have an obvious intensity change with the increased axial strain, and the strain sensitivity is negatively proportional to the length of TCF. The maximum sensitivity reaches $0.119 \mathrm{~dB} / \mu \varepsilon$, and less than a $0.1-\mu \varepsilon$ detection resolution is gained. In addition, owing to the flat wavelength shift, the cross-sensitivity caused by the ambient temperature is effectively constrained in $0.318 \mu \varepsilon /{ }^{\circ} \mathrm{C}$.

\section{Principles and Simulations}

As shown in Figure 1, the $t$-TCF structure is composed of lead-in and lead-out singlemode fibers (SMFs) and a section of tapered TCF, which is connected by a core-offset splicing technique (the core-offset value is denoted by $\alpha$ ). When the incident light reaches the first fusion point (Offset Joint 1, OJ1) through the lead-in SMF, one beam of light continues to transmit along the core of TCF and the other beam enters the cladding and excites the corresponding high-order cladding modes. Due to the different RI of the core and cladding of TCF, when two beams reach the second fusion joint (Offset Joint 2, OJ2), they will have a significant optical path difference and form a Mach-Zehnder interference.

(a)

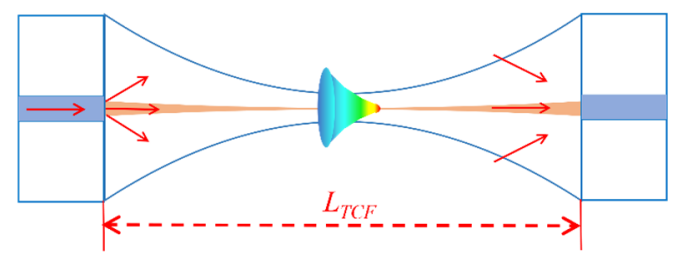

(b)
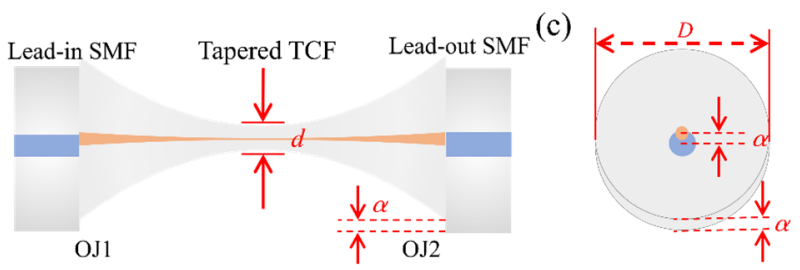

Figure 1. The schematic diagram of the $t$-TCF structure. (a) Top-view, (b) side-view and (c) crosssectional view.

According to the theory of dual-beam interference, the intensity of the transmission spectrum of an in-fiber MZI can be written as:

$$
I=I_{c o}+I_{c l}+2 \sqrt{I_{c o} I_{c l}} \cos \Delta \varphi
$$


where $I_{c o}$ and $I_{c l}$ are the light intensities in the core and cladding modes, respectively. $\Delta \varphi$ is the phase difference and equal to $2 \pi\left(n_{c o}-n_{c l}\right) \cdot L_{T C F} / \lambda_{i}$, where $\lambda_{i}$ is the wavelength of incident light, $L_{T C F}$ is the length of thin-core fiber, $n_{c o}$ and $n_{c l}$ are the effective RIs of core and cladding modes. Thus, we get $\Delta n_{\text {eff }}=n_{c o}-n_{c l}$. Furthermore, when $\Delta \varphi=(2 m+1) \pi$ $(m=1,2,3 \ldots)$, the resonance wavelength (denoted by $\left.\lambda_{m}\right)$ will be:

$$
\lambda_{m}=\frac{2 \Delta n_{e f f} L_{T C F}}{2 m+1}
$$

Additionally, the free spectral range (FSR) of the fringes can be expressed as:

$$
F S R=\lambda_{m}-\lambda_{m-1} \approx \frac{\lambda_{m}^{2}}{\Delta n_{e f f} L_{T C F}}
$$

Further, we define the normalized extinction ratio (ER) as:

$$
E R=\frac{2 \sqrt{I_{c o} I_{c l}}}{I_{c o}+I_{c l}}
$$

Equation (4) shows that the $E R$ value can reach its maximum when $I_{c o}=I_{c l}$, which is very important for an intensity modulation based fiber-optic sensor.

For an axial strain test, we define the distance between two fixed points as $L_{S}=L_{S M F}+L_{T C F}$, where $L_{S M F}$ is the length of SMF. Assume that $\Delta L_{S}$ is the variation of $L s$, the applied axial strain is then expressed as $S=\Delta L_{S} / L_{S}$. Different from the conventional modal interferometers reported in [34], the axial strain of $t$-TCF structure can be expressed as:

$$
S_{T C F}=\frac{L_{S} S}{L_{T C F}+L_{S M F} \frac{d^{2}}{D^{2}}}
$$

where $d$ is the diameter of taper waist, $D$ is the cladding diameter of SMF. Obviously, Equation (5) means that there is a negatively proportional relationship between $S_{T C F}$ and $d$ for a given D. Furthermore, the differential operation of Equation (5) is performed and we get:

$$
\Delta S_{T C F}=-k \frac{2 L_{s} d}{D} \Delta d
$$

where $k=L_{S} S /\left(L_{T C F}+L_{S M F} d^{2} / D^{2}\right)^{2}$. Equation (6) means that when an axial strain is applied, the increased $\Delta S_{T C F}$ will lead a tiny decrease in $d$. According to the principle of evanescent wave field, this reduced diameter of taper must bring a continuous loss of light energy. Therefore, in addition to the wavelength drift caused by photo-elastic effect [36], the intensity of fringes of $t$-TCF structure will be also changed significantly, which provides the possibility of intensity demodulation for axial strain sensing. Moreover, when $\Delta L_{S}$ is a small value, $k$ can be regarded as a constant and the intensity variation may be linearly decreased with the added axial strain.

In order to get a transmission spectrum with a high $E R$, the parameters of preparation and structure should be optimized. Then, the light field distribution of $t$-TCF structure is simulated by a beam propagation method. Typically, the central wavelength of incident light (i.e., $\lambda_{i}$ ) is $1550 \mathrm{~nm}$, and the background RI is equal to 1.0. Table 1 shows other key parameters, and the simulated results are presented in Figure 2. The light field energy distributions of $t$-TCF structure when $d=10-50 \mu \mathrm{m}$ are shown in Figure 2a. With the decrease in $d$, the energy loss of evanescent wave field gradually increases. Furthermore, from Figure $2 b$, the normalized energy change of light field is highly linear with the decreased $d$. By calculation, the loss coefficient is about $1 \%$ per micrometer. This means that with the increase (decrease) of axial strain (waist diameter), our tapered structure may exhibit an obvious and linear intensity variation. It is worth noting that due to the fact that a smaller waist diameter (e.g., less than $20 \mu \mathrm{m}$ ) will reduce the fusion efficiency, the target diameter of taper is set as $\sim 30 \mu \mathrm{m}$ in the following fabrication process. 
Table 1. The main parameters of the structure.

\begin{tabular}{cccc}
\hline Fibers & $\boldsymbol{n}_{\boldsymbol{c o}} / \boldsymbol{n}_{\boldsymbol{c l}}$ & Diameter $(\boldsymbol{\mu m})$ & Length \\
\hline lead-in/lead-out SMF & $1.4501 / 1.445$ & $8.3 / 125$ & - \\
un-tapered TCF & $1.46 / 1.445$ & $3.6 / 125$ & $15-50 \mathrm{~mm}$ \\
tapered TCF & $1.46 / 1.445$ & $0.3-1.44 / 10-50$ & $800 \mu \mathrm{m}$ \\
\hline
\end{tabular}

(a)

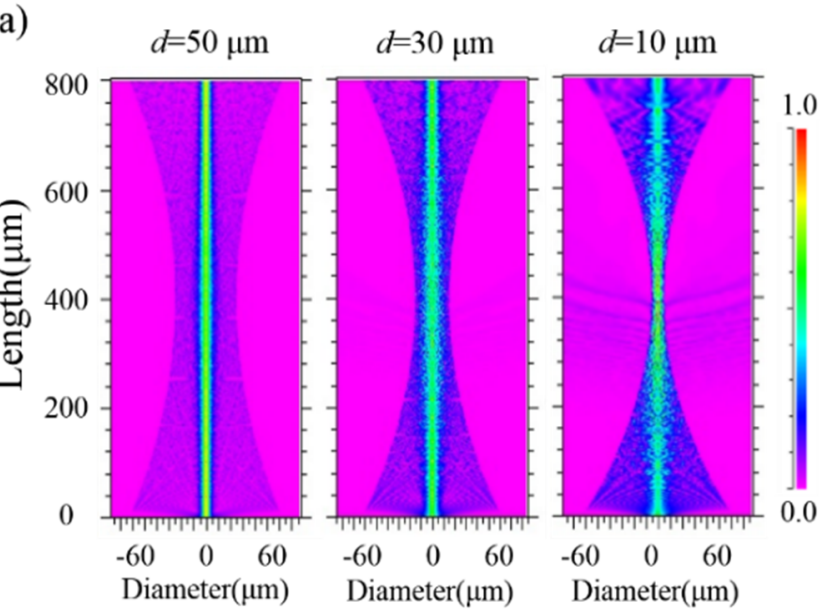

(b)

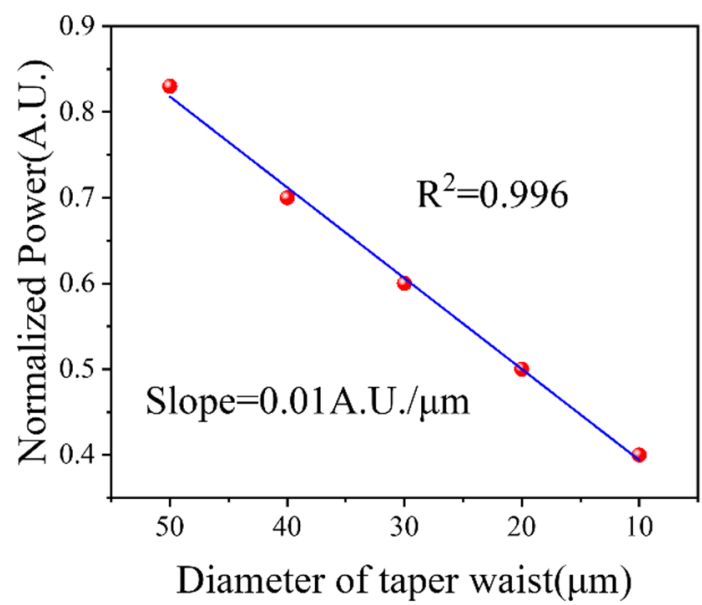

Figure 2. (a) Light field distributions of $t$-TCF structure and (b) normalized power with a varied diameter of taper waist.

\section{Fabrication}

As shown in Figure 3a, the fabrication of $t$-TCF structures includes two parts: symmetrical core-offset splicing and taper. The core-offset structure with $L_{T C F}=50 \mathrm{~mm}$ is completed in manual-mode by a commercial fusion splicer (KL-300T, with an adjustment resolution of $\sim 0.5 \mu \mathrm{m}$ ). The offset value is set at $\alpha=12 \mu \mathrm{m}$ and the fusion splicing loss is about $0.04 \mathrm{~dB}$. The key parameters for taper structure are set as follows: pre-discharge intensity and time are $40 \mathrm{bit}$ and $180 \mathrm{~ms}$, the main discharge intensity and time are $70 \mathrm{bit}$ and $2200 \mathrm{~ms}$, the waiting time is $1200 \mathrm{~ms}$ and the splicing speed is $0.17 \mu \mathrm{m} / \mathrm{ms}$. In addition, for comparison, three $t$-TCF structures are fabricated with similar waist diameters $(\sim 31 \mu \mathrm{m})$ and different $L_{T C F}$ (from $15 \mathrm{~mm}$ to $50 \mathrm{~mm}$ ). Table 2 shows the key structural parameters of the samples. The average waist diameter is $31.25 \mu \mathrm{m}$ with an error of less than $\pm 1.1 \mu \mathrm{m}$. In addition, the maximum difference of offset values is well constrained within $0.4 \mu \mathrm{m}$. This means that a high reproducibility (over $95 \%$ ) of our $t$-TCF structures can be achieved by simply an arc-discharge technique. Moreover, the fabricated taper 
structure with $L_{T C F}=50 \mathrm{~mm}$ is shown in Figure $3 \mathrm{~b}$. The diameter of taper is $30.12 \mu \mathrm{m}$ and the length of transition area is $774.4 \mu \mathrm{m}$. Then, three $t$-TCF structures are connected with a broadband light source (BBS, CONNET VENUS, with the range of 1525-1610 nm) and an optical spectrum analyzer (OSA, Agilent 86142B, with the resolution of $0.06 \mathrm{~nm} / 0.01 \mathrm{~dB}$ ). Their outputted transmission spectra are presented in Figure $3 c$. It is clear that when $L_{T C F}$ decreases from $50 \mathrm{~mm}$ to $15 \mathrm{~mm}$, the corresponding FSR of transmission spectrum inversely increases from $5.92 \mathrm{~nm}$ to $15.73 \mathrm{~nm}$. Moreover, the $E R$ values are also gradually increased and the maximum reaches $20.82 \mathrm{~dB}$ when $L_{T C F}=15 \mathrm{~mm}$.

(a)

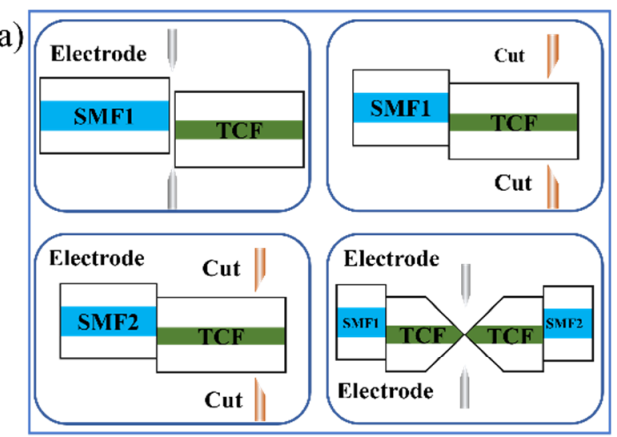

(b)

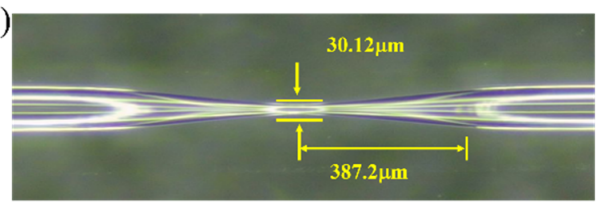

(c)

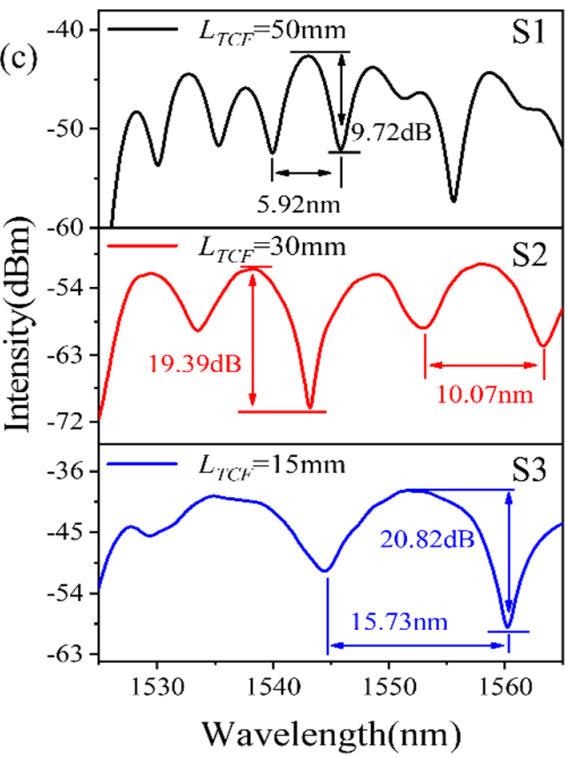

Figure 3. (a) Fabrication flow chart of $t$-TCF structure, (b) micro image of taper region, (c) transmission spectra with different $L_{T C F}$.

Table 2. Structural parameters of the samples.

\begin{tabular}{ccccc}
\hline Samples & $\boldsymbol{L}_{T C F}(\mathbf{m m})$ & Transition Areas $(\mu \mathrm{m})$ & Diameters $(\mu \mathrm{m})$ & Offset Values $(\mu \mathrm{m})$ \\
\hline S1 & 50 & 774.4 & 30.12 & $11.78 / 12.15$ \\
S2 & 30 & 765.6 & 32.25 & $12.37 / 11.93$ \\
S3 & 15 & 770.2 & 31.37 & $12.28 / 12.05$ \\
\hline
\end{tabular}

\section{Experiments and Results}

As shown in Figure 4, the experimental setup for axial strain sensing is mainly completed by a micro-displacement platform (Newport, CA, USA, Model ESP-300), with the minimum accuracy of $0.1 \mu \mathrm{m}$. For protection, the above three $t$-TCF structures are packaged into a thin steel tube with the diameter of $\sim 500 \mu \mathrm{m}$ (see the sub-figure). Then, the sensor heads are placed horizontally on both sides of the platform and fast fixed with UV glue. Specially, $L_{S}$ is equal to $10 \mathrm{~cm}$ and the ambient temperature is $25 \pm 0.2^{\circ} \mathrm{C}$. The axial strain tests are then performed, and their transmission spectra are demonstrated with the varied strain in Figure 5.

From Figure $5 \mathrm{a}$, when $L_{T C F}=50 \mathrm{~mm}$, its spectrum mainly shows an intensity variation as the strain increases. The intensity of dip is linearly increased at about $6.27 \mathrm{~dB}$. The corresponding sensitivity is $0.011 \mathrm{~dB} / \mu \varepsilon$, and the linearity is 0.993 in the range of $0-600 \mu \varepsilon$. When $L_{T C F}$ is reduced to $30 \mathrm{~mm}$ (see Figure $5 \mathrm{~b}$ ), the intensity sensitivity is lightly increased to $0.019 \mathrm{~dB} / \mu \varepsilon$, but the corresponding linear range is reduced to $0-250 \mu \varepsilon$. Comparatively, in the case of $L_{T C F}=15 \mathrm{~mm}$, the intensity sensitivity is greatly and linearly enhanced about 11 -fold, and reaches $0.121 \mathrm{~dB} / \mu \varepsilon$ in the range of $0-120 \mu \varepsilon$. The corresponding detection resolution is $0.08 \mu \varepsilon$ theoretically. Furthermore, the quantitative relationships are compared between intensity sensitivity/linear range and $L_{T C F}$. As shown in Figure 6, it is obvious that by simply reducing $L_{T C F}$ from $50 \mathrm{~mm}$ to $15 \mathrm{~mm}$, there is a gain of about 11-fold in the 
enhancement of intensity sensitivity, but the penalty is 5 times a deduction in the linear range (from $600 \mu \varepsilon$ to $120 \mu \varepsilon$ ).

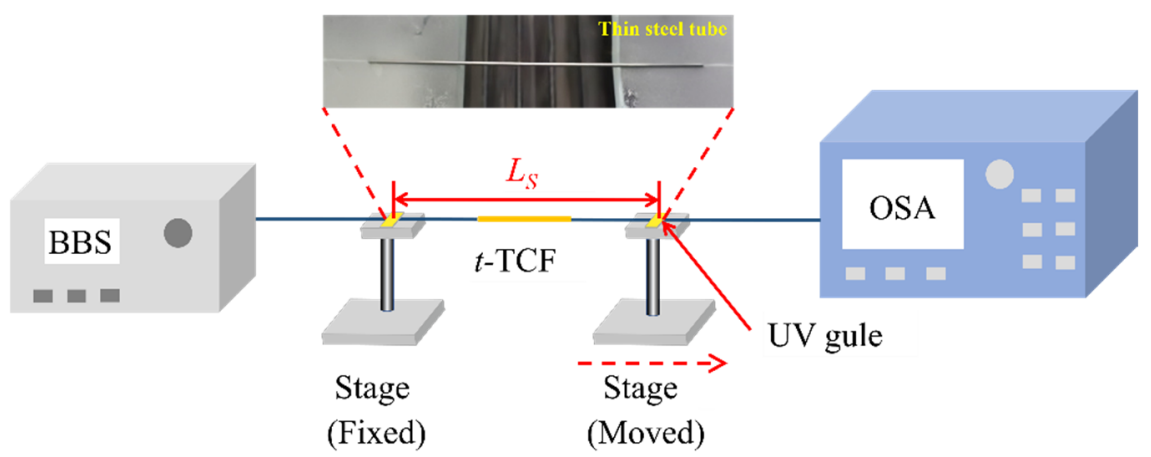

Figure 4. The experimental setup for axial strain sensing.
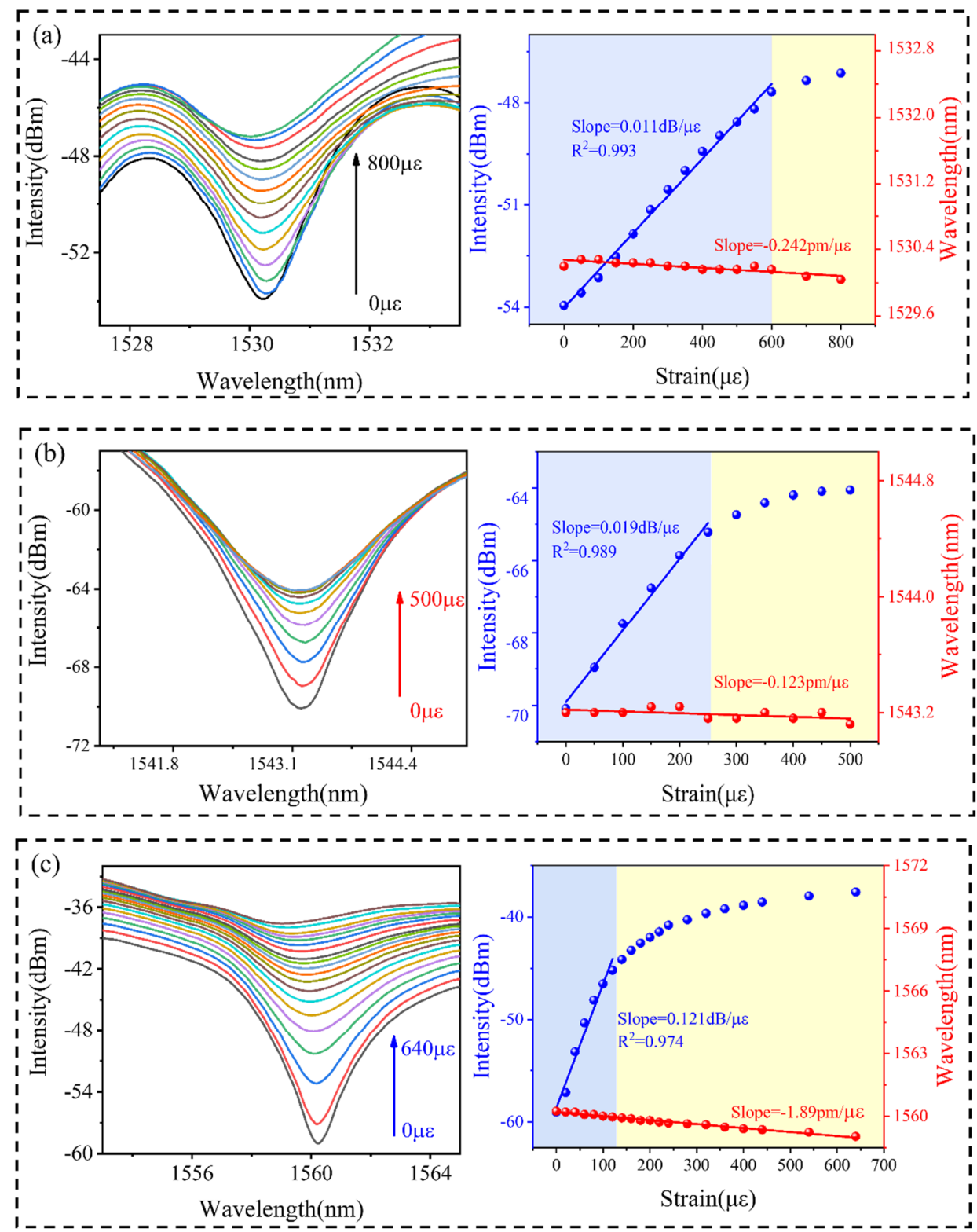

Figure 5. The transmission spectra of axial strain responses with different length of TCF. (a) $L_{T C F}=$ $50 \mathrm{~mm}$, (b) $L_{T C F}=30 \mathrm{~mm}$ and (c) $L_{T C F}=15 \mathrm{~mm}$. 


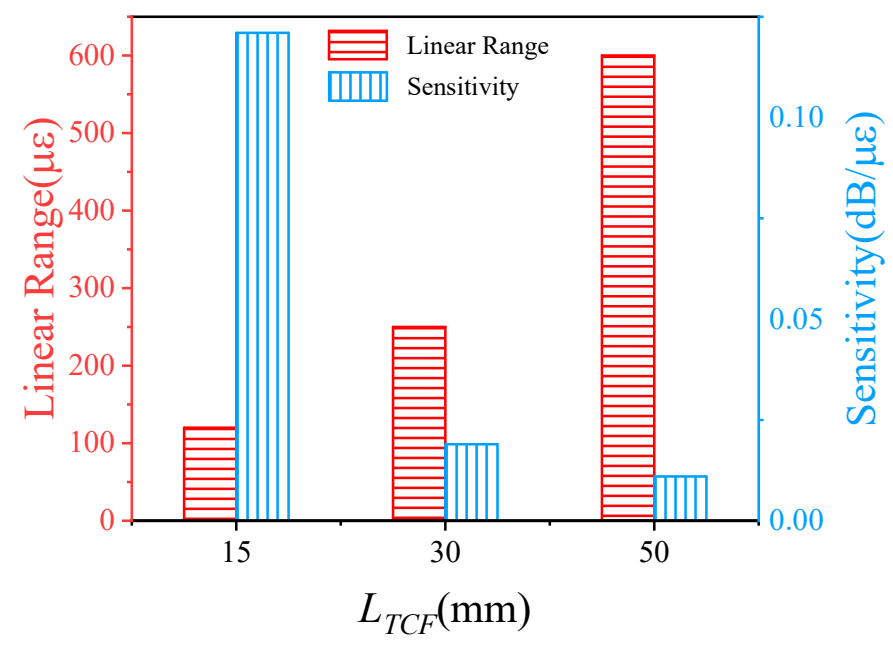

Figure 6. Comparison of sensitivities and linearity ranges with different $L_{T C F}$.

In addition, for these three samples, their wavelength responses are all blue-shifted, and the maximum sensitivity is merely $-1.89 \mathrm{pm} / \mu \varepsilon$ occurring in the sample of $L_{T C F}=15 \mathrm{~mm}$. Moreover, the sample with $L_{T C F}=15 \mathrm{~mm}$ is selected and multiple-time axial strain measurements are further conducted. As shown in Figure 7, with the increased and decreased axial strain, our structure exhibits better performance in term of repeatability. By calculation, the average intensity sensitivity is about $0.119 \mathrm{~dB} / \mu \varepsilon$, and the maximum deviation is less than $\pm 0.0021 \mathrm{~dB} / \mu \varepsilon$, which means that the error of repeatability is superior to $\pm 2 \%$.

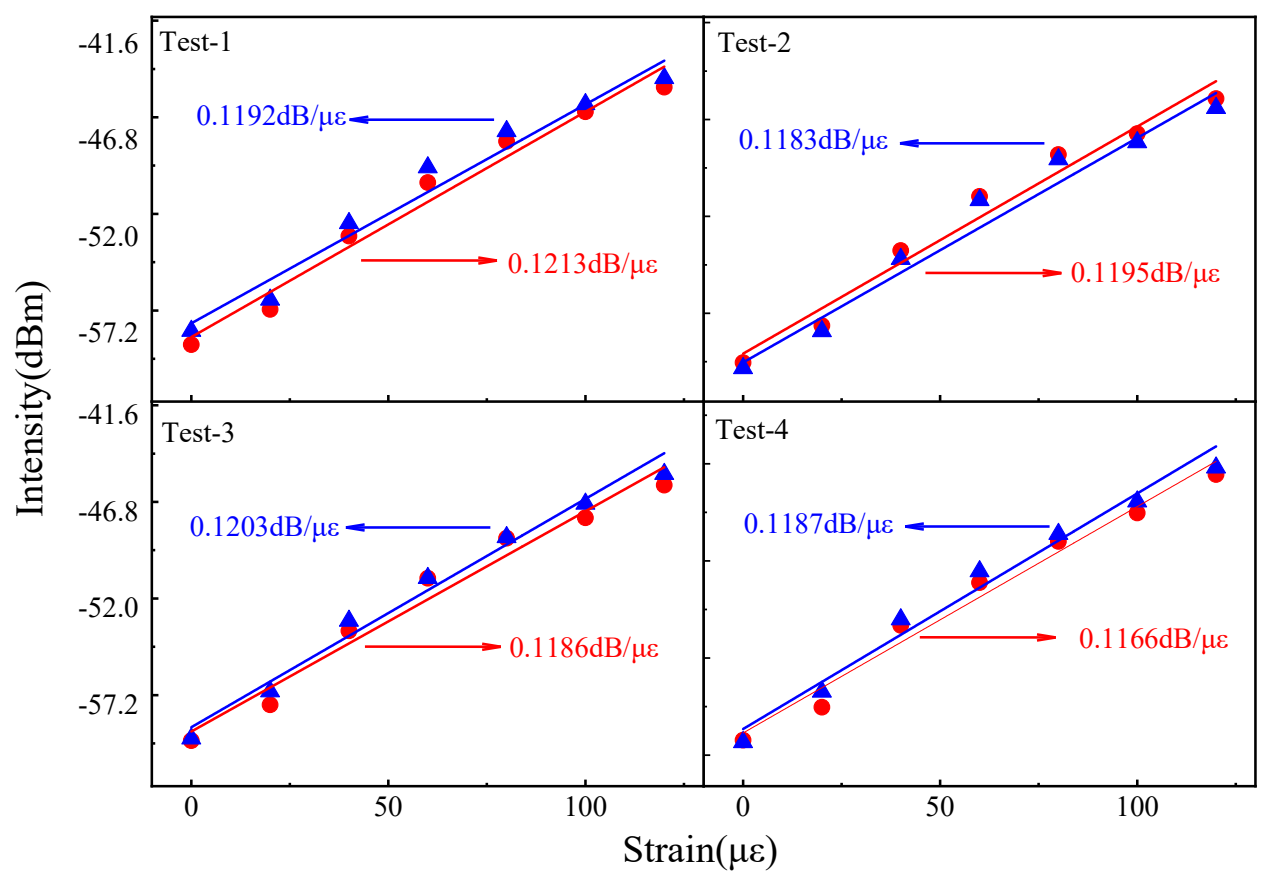

Figure 7. The relationships between intensity variation and increased/decreased axial strain.

Further, the sensor head with $L_{T C F}=15 \mathrm{~mm}$ is placed into a temperature chamber (LICHEN, 202-00T, Shanghai, China, with a resolution of $\pm 0.1^{\circ} \mathrm{C}$ ) to characterize the temperature response. As shown in Figure 8a, the transmission spectrum is red-shifted with the rise of temperature and the intensity of dip is increased by about $1.88 \mathrm{~dB}$. From Figure $8 \mathrm{~b}$, the wavelength sensitivity is $0.0736 \mathrm{~nm} /{ }^{\circ} \mathrm{C}$ with the linearity of $\sim 0.99$. The corresponding intensity sensitivity is merely $0.0381 \mathrm{~dB} /{ }^{\circ} \mathrm{C}$ in the range from $25{ }^{\circ} \mathrm{C}$ to $75{ }^{\circ} \mathrm{C}$. Therefore, the calculated cross-sensitivity caused by ambient temperature is $\sim 0.32 \mu \varepsilon /{ }^{\circ} \mathrm{C}$. 

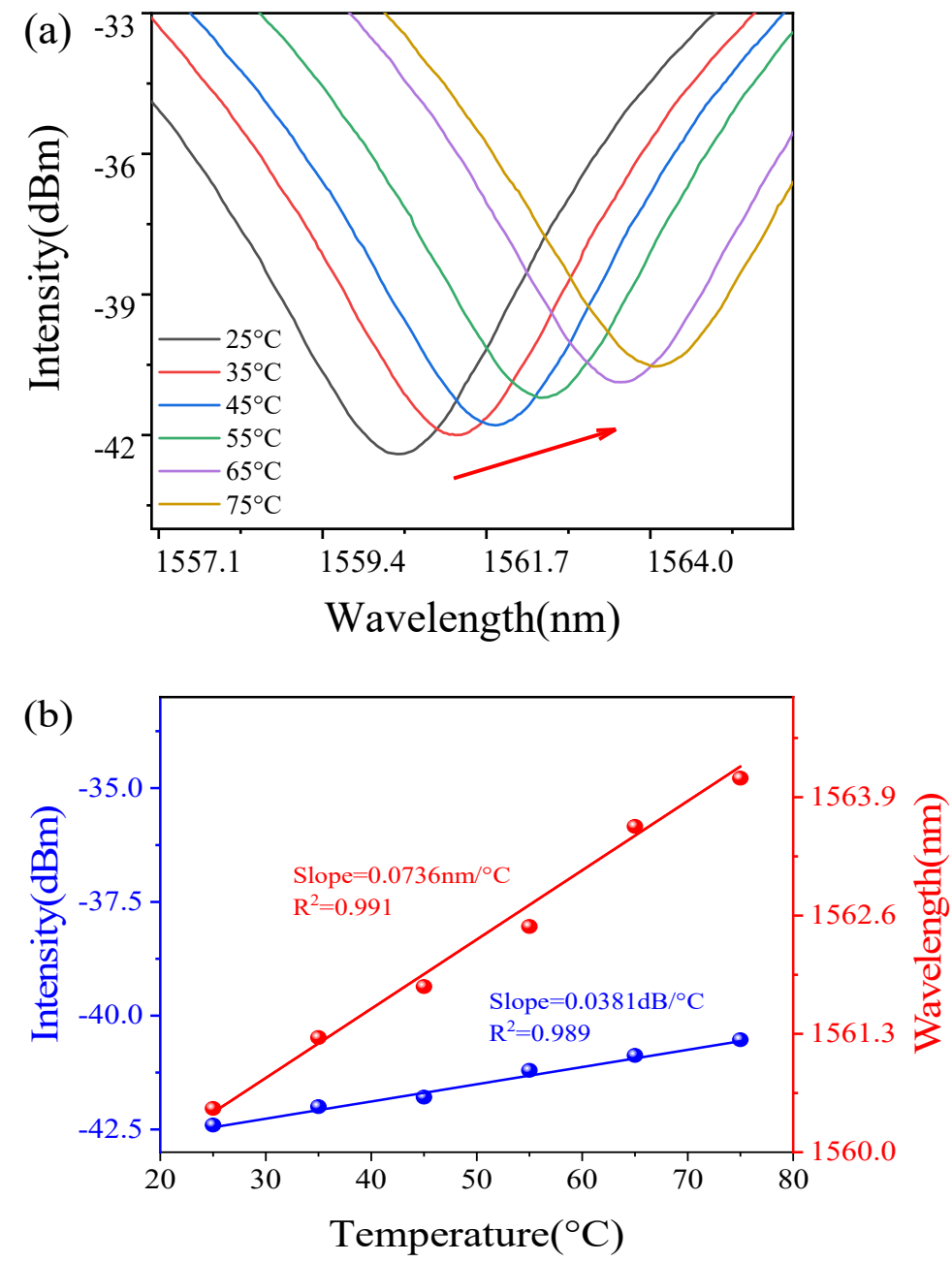

Figure 8. (a) Transmission spectrum of $t$-TCF structure $\left(L_{T C F}=15 \mathrm{~mm}\right)$ with varied temperature and (b) the relationship between intensity/wavelength variation and increased temperature.

Moreover, according to [27], the measured axial strain and temperature changes can be effectively discriminated by using the inverse matrix method shown as Equation (7).

$$
\left[\begin{array}{c}
\Delta \varepsilon \\
\Delta T
\end{array}\right]=\frac{1}{W}\left[\begin{array}{c}
k_{T I}-k_{T \lambda} \\
-k_{\varepsilon I} k_{\varepsilon \lambda}
\end{array}\right]\left[\begin{array}{c}
\Delta \lambda \\
\Delta I
\end{array}\right]
$$

where $W=k_{\varepsilon \lambda} k_{T I}-k_{\varepsilon I} k_{T \lambda}, \Delta \varepsilon$ and $\Delta T$ represent the changes in axial strain and temperature, respectively. $\Delta \lambda$ and $\Delta I$ represent the change of wavelength and intensity of fringe, respectively. $k_{\varepsilon \lambda}=-0.00189$ and $k_{\varepsilon I}=0.119$ are the wavelength and intensity response of strain, $k_{T \lambda}=0.0736$ and $k_{T I}=0.0381$ are the wavelength and intensity response of temperature. Therefore, we get the corrected sensitivity as $\sim 0.121 \mathrm{~dB} / \mu \varepsilon$, which means the measurement error of our sensor is less than $1.7 \%$. Table 3 compares the performance of fiber-optic strain sensors in terms of sensitivity, detection resolution and cross-sensitivity of temperature (note that the same resolution of $0.06 \mathrm{~nm} / 0.01 \mathrm{~dB}$ is adopted). It is clear that as far as intensity response is concerned, the $t$-TCF structure updates our previous record obtained by a microfiber based open cavity, and presents a sub-high and less than $0.1-\mu \varepsilon$ detection resolution, but with the advantage of ease of fabrication. Meanwhile, our sensor has the potential to be applied in a highly discriminative dual-parameter measurement because of the high temperature response $\left(73.6 \mathrm{pm} /{ }^{\circ} \mathrm{C}\right)$ and low cross-talk $\left(\sim 0.32 \mu \varepsilon /{ }^{\circ} \mathrm{C}\right)$. 
Table 3. Performance comparisons of the reported fiber-optic strain sensors.

\begin{tabular}{|c|c|c|c|c|c|}
\hline Sturctures & Sensitivity & Detection Resolution & Cross Senstivity & Linear Range & Refs \\
\hline Few-mode FBG & $2 \mathrm{pm} / \mu \varepsilon$ & $30 \mu \varepsilon$ & $17.15 \mu \varepsilon /{ }^{\circ} \mathrm{C}$ & $0-450 \mu \varepsilon$ & [15] \\
\hline SMF-PCF-SMF & $2.1 \mathrm{pm} / \mu \varepsilon$ & $28.6 \mu \varepsilon$ & $6.3 \mu \varepsilon /{ }^{\circ} \mathrm{C}$ & $0-3000 \mu \varepsilon$ & [18] \\
\hline FBG with FWX & $13.3 \mathrm{pm} / \mu \varepsilon$ & $4.51 \mu \varepsilon$ & $10.6 \mu \varepsilon /{ }^{\circ} \mathrm{C}$ & $0-137 \mu \varepsilon$ & {$[21]$} \\
\hline Filled high birefring-ent PCF & $25 \mathrm{pm} / \mu \varepsilon$ & $2.4 \mu \varepsilon$ & - & $0-61 \mu \varepsilon$ & [22] \\
\hline Panda-type PMF & $32 \mathrm{pm} / \mu \varepsilon$ & $1.875 \mu \varepsilon$ & - & $0-900 \mu \varepsilon$ & [24] \\
\hline Bubble based micro-cavity & $30.66 \mathrm{pm} / \mu \varepsilon$ & $1.95 \mu \varepsilon$ & $0.04 \mu \varepsilon /{ }^{\circ} \mathrm{C}$ & $0-600 \mu \varepsilon$ & [25] \\
\hline Dual-micro cavity & $1.15 \mathrm{~nm} / \mu \varepsilon$ & $0.052 \mu \varepsilon$ & $0.06 \mu \varepsilon /{ }^{\circ} \mathrm{C}$ & $0-230 \mu \varepsilon$ & [26] \\
\hline MS-HCF & $0.0036 \mathrm{~dB} / \mu \varepsilon$ & $2.78 \mu \varepsilon$ & - & $0-1000 \mu \varepsilon$ & [28] \\
\hline Up-tapered LPFG & $0.026 \mathrm{~dB} / \mu \varepsilon$ & $0.38 \mu \varepsilon$ & - & $0-590 \mu \varepsilon$ & [29] \\
\hline Core-offset TCF & $0.024 \mathrm{~dB} / \mu \varepsilon$ & $0.42 \mu \varepsilon$ & - & $0-700 \mu \varepsilon$ & [35] \\
\hline MMA-OC & $0.051 \mathrm{~dB} / \mu \varepsilon$ & $0.196 \mu \varepsilon$ & $0.106 \mu \varepsilon /{ }^{\circ} \mathrm{C}$ & $0-500 \mu \varepsilon$ & [30] \\
\hline tapered-TCF & $0.119 \mathrm{~dB} / \mu \varepsilon$ & $0.084 \mu \varepsilon$ & $0.32 \mu \varepsilon /{ }^{\circ} \mathrm{C}$ & $0-120 \mu \varepsilon$ & Our work \\
\hline
\end{tabular}

\section{Discussions}

According to Equation (5), the applied axial strain in fact can be magnified due to the reduced diameter of the taper waist. In theory, similar to the schemes reported in [24-26], the corresponding wavelength shift should be larger than that in an un-tapered structure. In our structure, under a suitable waist diameter, we experimentally prove that the energy loss of an evanescent wave field is very sensitive to the variation of the waist diameter caused by the increased or decreased axial strain. Thus, with an almost near-zero wavelength shift, the obvious intensity response of axial strain is gained by the proposed structure, which may provide a new method for intensity modulation based fiber-optic sensing and measurements.

In addition, the intensity sensitivity of our structure is negatively proportional to the length of the sensing unit. For a modal interferometer, the minimum length of TCF will be $\sim 10 \mathrm{~mm}$, which means that the sensitivity of our structure can be further improved but limited. Developing a new tapered TCF structure may be a possible solution, by combining the techniques of arc-discharge tapering and flame brush. More importantly, it is clear that there is a conflict between the sensitivity and linear range. In fact, the response range of the axial strain of the $t$-TCF structure can reach over $1000 \mu \varepsilon$ although the waist taper is reduced to $\sim 30 \mu \mathrm{m}$. Therefore, our future work will focus on gaining a tradeoff of strain sensitivity and linear range, through improving the package technique and introducing a lasing-sensor based scheme.

\section{Conclusions}

In this paper, a novel in-fiber Mach-Zehnder interferometer is proposed and fabricated based on the tapered TCF structure. The quantitative relationship between the energy loss of evanescent wave field and diameter of taper waist is gained, and the comprehensive tests are conducted in terms of axial strain and temperature under a suitable taper diameter $(\sim 31 \mu \mathrm{m})$. The experimental results prove that the intensity response of axial strain can be enhanced by simply reducing the length of the TCF. The $\sim 0.12 \mathrm{~dB} / \mu \varepsilon$ strain sensitivity is obtained when $L_{T C F}=15 \mathrm{~mm}$ with high repeatability, and the detection resolution can reach $0.084 \mu \varepsilon$. Moreover, the temperature cross-sensitivity is constrained within $0.32 \mu \varepsilon /{ }^{\circ} \mathrm{C}$ because of $<0.04 \mathrm{~dB} /{ }^{\circ} \mathrm{C}$ intensity fluctuation. With the merits of ease of fabrication and practicality, such an ultra-sensitive scheme is very potential in axial strain related engineering sensing. 
Author Contributions: Conceptualization, C.L.; methodology, C.L. and D.S.; validation, C.L., D.S. and H.Z.; writing - original draft preparation, C.L.; writing—review and editing, J.Y. and L.R. All authors have read and agreed to the published version of the manuscript.

Funding: This work was supported by Natural Science Foundation of China (Grant No. 61675066) and Project of the Central Government Supporting the Reform and Development of Local Colleges and Universities (Grant No. 2020YQ01).

Institutional Review Board Statement: Not applicable.

Informed Consent Statement: Not applicable.

Data Availability Statement: Data sharing not applicable.

Conflicts of Interest: The authors declare no conflict of interest.

\section{References}

1. Islam, R.; Ali, M.M.; Lai, M.-H.; Lim, K.-S.; Ahmad, H. Chronology of Fabry-Perot Interferometer Fiber-Optic Sensors and Their Applications: A Review. Sensors 2014, 14, 7451-7488. [CrossRef]

2. Peng, J.; Zhou, X.; Jia, S.; Jin, Y.; Xu, S.; Chen, J. High precision strain monitoring for lithium ion batteries based on fiber Bragg grating sensors. J. Power Sources 2019, 433, 226692. [CrossRef]

3. Koyama, Y.; Nishiyama, M.; Watanabe, K. Smart Textile Using Hetero-Core Optical Fiber for Heartbeat and Respiration Monitoring. IEEE Sens. J. 2018, 18, 6175-6180. [CrossRef]

4. Lopez-Higuera, J.M.; Cobo, L.R.; Incera, A.Q.; Cobo, A. Fiber Optic Sensors in Structural Health Monitoring. J. Light. Technol. 2011, 29, 587-608. [CrossRef]

5. Miliou, A. In-Fiber Interferometric-Based Sensors: Overview and Recent Advances. Photonics 2021, 8, 265. [CrossRef]

6. Zhang, L.; Liu, Y.; Gao, X.; Xia, Z. High temperature strain sensor based on a fiber Bragg grating and rhombus metal structure. Appl. Opt. 2015, 54, E109-E112. [CrossRef]

7. Feng, W.; Yang, X.; Yu, J.; Yue, Z. Strain and temperature sensor based on fiber Bragg grating cascaded bi-tapered four-core fiber Mach-Zehnder interferometer. J. Phys. D Appl. Phys. 2020, 53, 465104. [CrossRef]

8. Wang, Y. Review of long period fiber gratings written by $\mathrm{CO}_{2}$ laser. J. Appl. Phys. 2010, 108, 081101. [CrossRef]

9. Ascorbe, J.; Coelho, L.; Santos, J.L.; Frazao, O.; Corres, J. Temperature Compensated Strain Sensor Based on Long-Period Gratings and Microspheres. IEEE Photon. Technol. Lett. 2018, 30, 67-70. [CrossRef]

10. Carlos, M.; Arnaldo, L.J.; Rui, M.; Maria, D.; Catia, L.; Paulo, A.; Beatriz, O.; Paulo, A. Advances on polymer optical fiber gratings using a $\mathrm{KrF}$ pulsed laser system operating at $248 \mathrm{~nm}$. Fibers 2018, 6, 13. [CrossRef]

11. Soge, A.O.; Dairo, O.F.; Sanyaolu, M.E.; Kareem, S.O. Recent developments in polymer optical fiber strain sensors: A short review. J. Opt. 2021, 50, 299-313. [CrossRef]

12. Leal-Junior, A.; Avellar, L.; Frizera, A.; Marques, C. Smart textiles for multimodal wearable sensing using highly stretchable multiplexed optical fiber system. Sci. Rep. 2020, 10, 13867. [CrossRef] [PubMed]

13. Qureshi, K.K.; Liu, Z.; Tam, H.-Y.; Zia, M.F. A strain sensor based on in-line fiber Mach-Zehnder interferometer in twin-core photonic crystal fiber. Opt. Commun. 2013, 309, 68-70. [CrossRef]

14. Gong, H.; Chan, C.C.; Chen, L.; Dong, X. Strain Sensor Realized by Using Low-Birefringence Photonic-Crystal-Fiber-Based Sagnac Loop. IEEE Photon. Technol. Lett. 2010, 22, 1238-1240. [CrossRef]

15. Gao, X.; Ning, T.; Zhang, C.; Xu, J.; Zheng, J.; Lin, H.; Li, J.; Pei, L.; You, H. A dual-parameter fiber sensor based on few-mode fiber and fiber Bragg grating for strain and temperature sensing. Opt. Commun. 2020, 454, 124441. [CrossRef]

16. Dong, L.; Gang, T.; Bian, C.; Tong, R.; Wang, J.; Hu, M. A high sensitivity optical fiber strain sensor based on hollow core tapering. Opt. Fiber Technol. 2020, 56, 102179. [CrossRef]

17. Zhu, T.; Wu, D.; Liu, M.; Duan, D.-W. In-Line Fiber Optic Interferometric Sensors in Single-Mode Fibers. Sensors 2012, 12, 10430-10449. [CrossRef]

18. Zheng, J.; Yan, P.; Yu, Y.; Ou, Z.; Wang, J.; Chen, X.; Du, C. Temperature and index insensitive strain sensor based on a photonic crystal fiber in line Mach-Zehnder interferometer. Opt. Commun. 2013, 297, 7-11. [CrossRef]

19. Dash, J.N.; Negi, N.; Jha, R. Graphene Oxide Coated PCF Interferometer for Enhanced Strain Sensitivity. J. Light. Technol. 2017, 35, 5385-5390. [CrossRef]

20. Pang, M.; Xiao, L.M.; Jin, W.; Cerqueira S., A. Birefringence of Hybrid PCF and Its Sensitivity to Strain and Temperature. J. Light. Technol. 2012, 30, 1422-1432. [CrossRef]

21. Du, J.; Li, L.; Fan, X.; Liu, Q.; He, Z. Sensitivity Enhancement for Fiber Bragg Grating Sensors by Four Wave Mixing. Photonics 2015, 2, 426-439. [CrossRef]

22. Han, T.; Liu, Y.-G.; Wang, Z.; Guo, J.; Yu, J. A High Sensitivity Strain Sensor Based on the Zero-Group-Birefringence Effect in a Selective-Filling High Birefringent Photonic Crystal Fiber. IEEE Photon. J. 2018, 10, 7100109. [CrossRef]

23. Liu, Y.; Yu, C.Y. Highly stretchable hybrid silica/polymer optical fiber sensors for large-strain and high-temperature application. Opt Express 2019, 27, 20107-20116. [CrossRef] 
24. Ruan, J. High sensitivity Sagnac interferometric strain sensor based polarization maintaining fiber enhanced coupling. IET Optoelectron. 2021, 15, 48-51. [CrossRef]

25. Yin, C.C.; Cao, Z.G.; Zhang, Z.; Shui, T.; Wang, R.; Wang, J.; Lu, L.; Zhen, S.L.; Yu, B.L. Temperature-independent ultrasensitive Fabry-Perot all-fiber strain sensor based on a bubble-expanded microcavity. IEEE Photon. J. 2014, 6, 1-9. [CrossRef]

26. Tian, J.J.; Li, Z.G.; Sun, Y.X.; Yao, Y. High-sensitivity fiber-optic strain sensor based on the vernier effect and separated Fabry-Perot interferometers. J. Lightw. Technol. 2019, 37, 5609-5618. [CrossRef]

27. Kang, J.; Yang, J.; Zhang, X.; Liu, C.; Wang, L. Intensity Demodulated Refractive Index Sensor Based on Front-Tapered SingleMode-Multimode-Single-Mode Fiber Structure. Sensors 2018, 18, 2396-2404. [CrossRef]

28. Zheng, Y.; Shum, P.P.; Liu, S.; Li, B.; Auguste, J.-L.; Humbert, G.; Luo, Y. Strain sensitivity enhancement based on periodic deformation in hollow core fiber. Opt. Lett. 2020, 45, 3997-4000. [CrossRef] [PubMed]

29. Wang, Y.; Shen, C.; Lou, W.; Shentu, F. Intensity modulation type fiber-optic strain sensor based on a Mach-Zehnder interferometer constructed by an up-taper with a LPG. Opt. Commun. 2016, 364, 72-75. [CrossRef]

30. Zhang, H.; Zhang, M.; Kang, J.; Zhang, X.D.; Yang, J.R. High sensitivity fiber-Optic strain sensor based on modified microfiberassisted open-cavity Mach-Zehnder interferometer. J. Lightw. Technol. 2021, 39, 4556-4563. [CrossRef]

31. Khalifa, A.B.; Cherif, R.; Salem, A.B. Ultrahigh sensitivity with different taper geometries of thin-core fiber modal interferometer for refractive index sensing. Opt. Eng. 2019, 58, 026109. [CrossRef]

32. Huang, X.; Li, X.; Yang, J.; Tao, C.; Guo, X.; Bao, H.; Yin, Y.; Chen, H.; Zhu, Y. An in-line Mach-Zehnder Interferometer Using Thin-core Fiber for Ammonia Gas Sensing with High Sensitivity. Sci. Rep. 2017, 7, 44994. [CrossRef]

33. Kong, Y.; Shu, X.; Cao, H.; Deng, J. Thin-Core Fiber Taper-Based Multi-Mode Interferometer for Refractive Index Sensing. IEEE Sens. J. 2018, 18, 8747-8754. [CrossRef]

34. Zhang, X.; Liu, C.; Liu, J.; Yang, J. Single Modal Interference-Based Fiber-Optic Sensor for Simultaneous Measurement of Curvature and Strain with Dual-Differential Temperature Compensation. IEEE Sens. J. 2018, 18, 8375-8380. [CrossRef]

35. Hou, L.T.; Liu, J.P.; Liu, X.J.; Zhang, X.D.; Yang, J.R.; Ran, L.L. Comparisons of Strain Response in Symmetric and Asymmetric Single-Mode-Thin-Core Single-Mode Fiber Structures. In Proceedings of the Asia Communication and Photonics (ACP), M4A.135, Chengdu, China, 2-5 November 2019.

36. Yoon, M.-S.; Park, S.; Han, Y.-G. Simultaneous Measurement of Strain and Temperature by Using a Micro-Tapered Fiber Grating. J. Light. Technol. 2012, 30, 1156-1160. [CrossRef] 